João Pessoa, v.6, n.2, p.81-94, mai./ago. 2018. ISSN 2318-1001

DOI:10.18405/recfin20180205

Disponível em: http://periodicos.ufpb.br/ojs2/index.php/recfin

\title{
A CONTABILIDADE DO CRIME NO BRASIL: AVANÇOS E DESAFIOS ${ }^{1}$
}

\section{THE ACCOUNTING OF CRIME IN BRAZIL: ADVANCES AND CHALLENGES}

\author{
Hermes Oliveira Gomes \\ Mestrando em Contabilidade pela Universidade Federal da Bahia \\ hermesk@hotmail.com \\ https://orcid.org/0000-0003-0304-9646 \\ Magno Oliveira Ramos \\ Mestrando em Contabilidade pela Universidade Federal da Bahia \\ magnusso1@yahoo.com.br \\ https://orcid.org/0000-0002-2825-7145 \\ Maria Valesca Damásio De C. Silva \\ Doutora em Administração pela Universidade Federal da Bahia \\ Professora da Universidade Federal da Bahia \\ mvalesca.ufba@gmail.com \\ https://orcid.org/0000-0002-4597-8868 \\ Larissa Maiara Vieira Dos Santos \\ Graduação em Ciências Contábeis pela Universidade Federal da Bahia \\ larissa.mvs@outlook.com \\ https://orcid.org/0000-0003-4299-8350
}

\section{RESUMO}

Objetivo: Apresentar os resultados alcançados, após a obrigatoriedade de envio de informações dos serviços de contabilidade expedidas ao Conselho de Controle de Atividades Financeiras (COAF).

Fundamento: Neste trabalho, a discussão partiu da análise das informações disponíveis do no banco de dados do COAF, referente às comunicações enviadas por órgãos parceiros no combate a crimes, lavagem de dinheiro, sonegação fiscal, entre outros.

Método: $\mathrm{O}$ trabalho caracteriza-se como exploratório, com análise de dados pré-existentes no banco de dados do COAF, no período dos anos de 2004 a 2015, particularmente, a partir de 2014, quando houve a obrigatoriedade dos envios. A abordagem do problema foi classificada como quantitativa,

\footnotetext{
${ }^{1}$ Artigo recebido em: 24/09/2017. Revisado por pares em: 03/11/2017. Reformulado em: 14/12/2017. Recomendado para publicação em: 28/02/2018 por Luiz Felipe de Araújo Pontes Girão (Editor Geral). Publicado em: 30/04/2018. Organização responsável pelo periódico: UFPB.

Endereço: Av. Reitor Miguel Calmon, s/n, Vale do Canela, $3^{\circ}$ andar. Salvador-BA.

DOI: http://dx.doi.org/10.18405/recfin20180205
} 
tendo em vista que se apoderou do teste de estatística descritiva e da verificação de dados estatísticos para efetuar todas as análises.

Resultados: Com o estudo, constatou-se uma pequena queda das informações repassadas ao órgão, como também, uma maior retração das interpelações institucionais e como ainda são grandes os desafios em prol ao combate de crimes nos meios empresarias.

Contribuições: Os achados deste estudo contribuem para a discussão em torno da criação de uma consciência nos profissionais e entidades contábeis em relação ao papel da contabilidade como ferramenta útil no combate ao crime contra a ordem tributária. Também, levanta possibilidades de estudos futuros, pesquisando relações que não são estudadas, já que não existem trabalhos que se debrucem sobe o recorte apresentado.

Palavras-Chave: Contabilidade do Crime. Lavagem de Dinheiro. Crime contra a Ordem Tributária. Lei Anticorrupção.

\section{ABSTRACT}

Objective: To present the results achieved, after an obligation to send information from the accounting services sent to the Financial Activities Control Council (COAF).

Background: In this work, a discussion of the analysis of the information available in the COAF database, referring to communications sent by partner agencies without fighting crime, money laundering, tax evasion, among others.

Method: The work is characterized as exploratory, with analysis of pre-existing data without COAF database, no period from the years 2004 to 2015, particularly, from 2014, when there was an obligation of the shipments. An approach to the problem was classified as quantitative, taking into account that it took over the test of descriptive statistics and the verification of statistical data to perform all as analyzes.

Results: With the study, there was a small drop in information sent to the agency, as well as a greater retraction of the institutional interpellations, and the challenges to fight crimes in business circles are still great.

Contributions: The findings of this study contribute to a discussion around creating an awareness of our accounting professionals and entities regarding the role of accounting as useful. Also, it raises possibilities for future studies, researching relationships that are not studied, since there are no studies that look at the clipping.

Keywords: Crime Accounting. Money laundry. Crime against a Tax Order. Anti-Corruption Law.

\section{INTRODUÇÃO}

Nas últimas décadas, o mundo e particularmente o nosso país passa por um cenário marcado por inúmeros escândalos de corrupção, mau uso do dinheiro público e crimes de ordem tributária. Este cenário é visível, e vem ameaçando visceralmente as práticas contábeis no Brasil. Hoje tramitam, em varas de primeira instância, 5.861 processos relativos a crimes financeiros em todo o Brasil, como ocultação de bens e lavagem de dinheiro. Estados como Mato Grosso tem o segundo maior número de processos, 613 e no Paraná, outros 331. Entre eles, estão os relacionados à Operação Lava Jato. O Brasil possui hoje 27 varas federais especializadas em crimes contra o Sistema Financeiro Nacional e de lavagem e ocultação de bens. Essas varas federais estão em 14 estados e no Distrito Federal. Nos demais estados, as ações tramitam em varas criminais comuns. 
Diante disso, as mudanças recentemente introduzidas passaram a indicar, mais ainda, o papel dos profissionais e organizações contábeis diretamente no rol dos obrigados a prestar informações ao Conselho de Controle de Atividades Financeiras (COAF). Assim, os profissionais de contabilidade têm ocupado o centro da arena de discussões. Consoante a esse quadro é possível identificar que a responsabilidade civil, penal e administrativa do profissional e da organização contábil os tornam suscetíveis aos riscos e penalidades.

A Lei 9.613 sancionada em 1998 definiu o crime a lavagem de dinheiro, sendo caracterizado por um conjunto de operações comerciais ou financeiras que buscam a incorporação na economia de cada país, de modo transitório ou permanente, de recursos, bens e valores de origem ilícita e que se desenvolvem por meio de um processo dinâmico que envolve, teoricamente, três fases independentes (colocação, ocultação e integração) que, com frequência, ocorrem simultaneamente.

Em seguida, o COAF surgiu no mesmo ano, com um órgão do Ministério da Fazenda, cuja missão é identificar informações suspeitas. Vale salientar que muitas investigações, como a própria Operação Lava-Jato, nasceram de notificações do COAF. Outro marco importante foi a aprovação, em 2012, da Lei 12.683, que tornou mais rigorosa as penas de crimes de lavagem de dinheiro ou ocultação de bens, direitos e valores. Em 2012 os profissionais e organizações contábeis foram incluídos no rol de responsáveis pela prestação de informações ao COAF. Essa obrigatoriedade se deu em função da Lei n. ${ }^{\circ}$ 12.683/12.

Desta forma, a contabilidade assume papel importante, acompanhando as mudanças, tendo reflexo da legislação brasileira e da própria sociedade. Percebe-se ainda que, no Brasil, muitos crimes de ordem tributária, como, por exemplo, os de lavagem de dinheiro ocupam o centro da atenção da mídia. O processo de construção de uma contabilidade voltada para a correção, fiscalização e controle de práticas fraudulentas motivou o COAF a acrescentar os serviços de contabilidade no âmbito de atividades que, em virtude de sua relevância, necessitam ser controladas e informadas.

Diante deste cenário, a questão de partida que orienta este estudo é: Qual o tratamento dado às informações dos serviços de contabilidade após a obrigatoriedade imposta pelo COAF? O objetivo deste trabalho é apresentar os resultados alcançados após a obrigatoriedade de envio de informações dos serviços de contabilidade ao COAF.

A hipótese testada é: após esta nova obrigação a sociedade será protegida contra a utilização indevida de serviços contábeis para atos ilícitos. A hipótese poderá ser confirmada apenas com o tratamento adequado das informações dos serviços de contabilidade. Do contrário, não haverá controle das informações, a prevalência e incidência dos crimes resultarão em sanções penais previstas em lei, além dos riscos da imagem, pela associação do responsável com as organizações criminosas.

Para alcançar o objetivo pretendido, serão apresentados os resultados, após a obrigatoriedade, desde 2014, de comunicação dos serviços de contabilidade ao COAF. Para tanto a pesquisa, fundamentalmente, do tipo exploratório-descritiva, de natureza qualitativa, baseada em documentos e referenciais teóricos de estudos na área, buscará evidenciar os resultados.

\section{REFERÊNCIAL TEÓRICO}

\subsection{Crimes Fiscais Contra o Estado Brasileiro}

Em uma sociedade cada vez mais exigente, fiscalizadora e, sobretudo, atenta aos acontecimentos, cresce os anseios para o exercício do controle (Tatagiba, 2010). Este quadro pode ser visto nos trabalhos de Ribeiro (2002), Tatagiba (2010), Gohn (2010), Britto (1992), Avritzer (2007) e Lehman e Okcabol (2005).

Diante da prevalência de crimes fiscais no Estado Brasileiro, a contabilidade busca mecanismos para combatê-los ou, pelo menos, controlá-los (Golden, Skalke \& Clayton, 2011). É verdade que 
crimes de ordem tributária são comuns no Brasil e demais nações desenvolvidas e em desenvolvimento. Grande parte deles é responsável pelos esquemas de corrupção. Em certa medida, crimes desta natureza trazem danos ao erário, indicando ainda mau uso do dinheiro público (Lehman \& Okcabol, 2005). Em termos de Setor Público, a sonegação de impostos, por exemplo, ameaça as receitas do próprio Estado, e, amiúde, provoca uma diminuição dos recursos financeiros que seriam empregados na manutenção de atividades essências, reduzindo, desta forma, o nível de qualidade de vida dos cidadãos (Júnior \& Moreira, 2011).

Em termos de combate aos crimes fiscais, o Estado Brasileiro apresentou certo avanço, motivado não somente pela atual legislação, como também pela ascensão das instituições responsáveis pela fiscalização e controle (Roncato, 2006). Dentre tais avanços pode-se citar: a legislação que trata da obrigatoriedade de prestação de contas pelos gestores públicos; a atuação da Receita Federal no controle da renda dos cidadãos; a atuação mais efetiva e atenta das Instituições Públicas de Controle Social (IPCS); o rigor maior da legislação que trata de crimes contra a ordem tributária; e etc. Contudo, mesmo diante de um cenário que demostra superação de obstáculos que dificultavam o controle e fiscalização, bem como do advento da tecnologia da informação e dos avanços significativos nesta área, ainda persistem desafios a serem superados, pois assim como o combate ao crime, os criminosos vão ao longo do tempo sofisticando seus mecanismos de ludibriar as instituições públicas e as de fiscalização.

Junior e Moreira (2011) falam que no combate aos crimes fiscais, o controle do Estado é observado tanto no poder como no dever, que a própria Administração (ou outro Poder) tem de vigiar, orientar e corrigir, diretamente, ou por meio de órgãos especializados, a sua atuação administrativa e a dos demais entes. Historicamente, alguns eventos relacionados com crimes fiscais sempre estiveram presentes na sociedade (Gouvêa \& Avanço, 2006). Entretanto, há uma tendência mundial, no sentido de inibir a promoção de fraudes e outros crimes, principalmente, contra o erário público. A sociedade, constantemente, passa por situações que refletem a sonegação e desvio de recursos. Temas como lavagem de dinheiro é refletido nas sociedades modernas, como é o caso do Brasil. Segundo Roncato (2006):

A fim de garantir uma boa visibilidade no panorama internacional, o país participou de diversos encontros multilaterais que abordaram o tema da lavagem de dinheiro, como a Convenção de Viena em 1988, a Convenção de Estrasburgo em 1990 e a Convenção de Palermo de 2000, entre outros. Sendo signatário dessas Convenções o Brasil se comprometeu a incorporar em seu ordenamento jurídico mecanismos de combate à lavagem de dinheiro. Esse compromisso se materializou com a Lei no ${ }^{0.613,}$ de 03 de março de 1998.

Então, crimes como lavagem de dinheiro e contra a ordem tributária representam uma afronta à autonomia do Estado. Desta forma, a existência de crimes desta natureza indica a real necessidade de um controle de supostas informações fundadas em práticas ilícitas, com instauração dos procedimentos cabíveis (COAF, 2015). Com isso, essa atuação, reduzirá a ocorrência de ilícitos. Afinal, crimes como estes contribuem para o aumento da insatisfação da sociedade. Os Crimes de sonegação fiscal estão previstos na Lei 4.729/1965, embora a doutrina majoritária entenda que essa Lei fora revogada tacitamente pela Lei 8.137/1990 que trata dos crimes contra a ordem tributária. A Lei 4.729/1965 trouxe a definição de crime de sonegação fiscal como comportamentos descritos de forma casuística, estando relacionado com o dever tributário. Essa lei fora criada com o desejo das autoridades que pretendiam utilizar dessa norma legal com a intenção de intimidar os contribuintes que sonegavam os impostos.

Atualmente, o Ministério da Fazenda e o Banco Central desenvolvem um esforço conjunto para coibir crimes tributários, como as práticas de lavagem de dinheiro, procurando "cercar" áreas 
que não tinham muita atenção. É o caso agora das Administradoras de Consórcios, que precisam ficar atentas com relação às situações ditas "anormais".

Os delitos contra a ordem tributária representam um dos temas jurídicos bastante complexos da atualidade. Neste cenário, as diversas implicações destes crimes no ordenamento jurídico nacional são visíveis. Mas para dizer-se consumado o crime, é preciso que todos os elementos de sua caracterização estejam presentes, conjuntamente, tais como omitir informação, fraudar a fiscalização, elaborar documento falso, entre outros.

\subsection{Combate a Contabilidade do Crime: Ação Conjunta no Combate à Má Conduta dos Contado- res}

A sigla COAF significa "Conselho de Controle de Atividades Financeiras". Trata-se de uma entidade do Ministério da Fazenda (MF), criada como uma Unidade de Inteligência Financeira (UIF) que atua na prevenção dos crimes de lavagem de dinheiro, definido pela Lei 9.613 de março de 1998. $\mathrm{O} C \mathrm{COAF}$ atua no território brasileiro, mas se interliga com os vários órgãos internacionais. O COAF exerce vigilância sobre todo o sistema financeiro brasileiro e atividades supervisionadas pelo Banco Central do Brasil: bancos, corretoras de valores, distribuidoras, casas de câmbio, administradoras de consórcios, entre outros. Por exemplo, os consórcios não são, stricto sensu, instituições financeiras pelo fato de que são normatizadas e controladas pelo Banco Central do Brasil (BACEN), mais de certa forma estão também sob a vigilância do COAF ( COAF, 1998).

Neste aspecto, um exemplo de atuação do COAF, refere-se às operações consideradas "anormais" equivalem às movimentações de dinheiro de origem suspeita e/ou duvidosas, às vezes em espécie, às vezes incompatíveis aparentemente com a renda formal da pessoa física ou jurídica. A entidade financeira é obrigada, então, a relatar formalmente ao COAF, mas são proibidas de informar ao cliente. Assim, o sofisticado sistema integrado do COAF e do MF que irá avaliar a eventual ilegalidade e se isso se caracterizar, procede o desenvolvimento da denúncia ao Ministério Público e este à Polícia Federal, que abrirão processos de averiguação. Portanto os leitores devem acompanhar o noticiário e tendências atuais neste assunto, porque o tema é sério e importante para os brasileiros, devendo estes zelar pelo uso, controle e fiscalização de recursos públicos, bem como qualquer outra forma de crimes conta o erário.

No combate aos crimes fiscais, o Conselho Federal de Contabilidade (CFC), em conjunto com o Instituto dos Auditores Independentes do Brasil (IBRACON) e a Federação Nacional de Contabilidade (FENACON), desenvolveram estudos junto ao COAF de modo a regulamentar a aplicação da Lei pela Lei 9.613, no âmbito da classe contábil brasileira. Desta forma, se concretiza o papel dos profissionais de contabilidade como agentes protagonistas neste processo. Por outro lado, vale ressaltar que, a atuação do COAF, no contexto moderno retrata as recentes adaptações ocorridas em diversos países, com intuito de coibir atividades criminosas (Lehman \& Okcabol, 2005).

No caso brasileiro, a promulgação da Lei 12.683/12, que alterou e ampliou o alcance da Lei 9.613/98 não pode ser considerada uma novidade ou "modismo" criado no Brasil. Um paralelo feito com muitos países leva a conclusão de que estes já passaram por este estágio. Adicionalmente, tais países exercem esta disciplina, através da aplicação de penas administrativas, após receberem, examinarem e identificarem as ocorrências suspeitas de atividades ilícitas, com o tratamento adequado das informações (Doost, 1999).

Por isso que se justifica a necessidade de uma legislação no Brasil específica, no intuito de coibir as irregularidades. Assim, o contexto atual demanda, portanto, aderência às normas vigentes e a prática de regulamentação dessas normas no Estado brasileiro. Neste ínterim, Golden et al (2011) alerta que a contabilidade assume grande papel como ferramenta de gestão, tomada de decisões, controle e fiscalização inter-relacionada institucionalmente com a identificação e caracterização de crimes. Como por exemplo, a realização de exames periódicos de auditoria interna e externa; as 
ações envolvendo os controles de operações suspeitas; fiscalização e acompanhamento realizado de atos e/ou fatos que envolvam a contabilidade; dentre outros.

Discutir a contabilidade como instrumento para o combate ao crime não é um tema novo. Mas, o fato é que os interessados nas informações contábeis, como acionistas, administradores, gestores e a própria sociedade, se utilizam da contabilidade para atender necessidades individuais. Esta ânsia leva às práticas ilícitas, que "maquiam" as informações contábeis. De acordo com Silva (2012), para que se realize a prevenção destas práticas é necessário que as demonstrações contábeis sejam analisadas e revisadas minuciosamente, então serão úteis nas investigações de fraudes.

A prática contábil sempre se preocupou com as fraudes ocorridas em diversos contextos em que está inserida. (Ribeiro, 2002). Isso motiva as ações do COAF, no sentido de combater a contabilidade do crime no Brasil. Além disso, a contabilidade, como ciência, sempre buscou evitar colapsos financeiros, má gestão e distorções nas grandes corporações (Lehman \& Okcabol, 2005).

Informações concernentes à atividade contábil no Brasil, tradicionalmente, sempre foram objeto de fiscalização e controle pelo próprio Estado brasileiro. Por isso a ação conjunta dos órgãos responsáveis tem por objetivo: identificar agentes que auferem renda dentro de limites da tributação do imposto de renda; emitir estatísticas relacionadas com emprego e renda feita pela declaração de cadastro geral de emprego e desemprego; avaliar salários com objetivo de traças programas sociais, bem como outras atividades. Destarte, as atividades financeiras realizadas pelos bancos também são fiscalizadas pelo BACEN.

Debates envolvendo o tema fraude e crimes na contabilidade são comuns nos United States of America (EUA) (Lehman \& Okcabol, 2005). Neste sentido, se exige um Estado mais operante e rigoroso, e o Brasil precisa alcançar esse padrão. Para tanto, o Estado brasileiro necessita de informações, não só para tomada de decisões, como também para subsidiar sua atuação de forma a orientar a política econômica do país, e combater a contabilidade criminosa. Emerge, portanto, um panorama em que as informações encaminhadas ao COAF devem originar-se de fontes confiáveis, ou seja, um cenário que retrate a realidade. Uma ação conjunta entre o COAF e demais órgãos de controle evidenciará aquelas operações suspeitas de fraudes, bem como um controle daquelas aparentemente lícitas.

Em suma, é preciso salientar que, mesmo o controle de informações contábeis e financeiras ser um tema em franco debate no Brasil, a preocupação em compartilhar informações emergiu recentemente. O ineditismo relacionado com encaminhamento de informações contábeis ao COAF, e a ação conjunta com demais entidades, traz grandes repercussões dentro da sociedade e do próprio Estado. Afinal, pela relevância de tratar-se de informações de interesse coletivo, tem o poder de impactar e impressionar (Golden et al, 2011). Em se tratando dos usuários das informações contábeis, revela, outrossim, uma proteção contra a utilização indevida de informações ilícitas. Serve de proteção também contra as sanções penais previstas em lei, além dos riscos de ter uma imagem e nome associados com organizações criminosas (Júnior \& Moreira, 2011).

Combater a má conduta daqueles que exercem atividades contábeis é essencial em um Estado Democrático de Direito e pais em desenvolvimento, como o Brasil. Uma profissão que evolui junto com o Estado, caso da contabilidade, deve deixar-se se transformar pelas tendências futuras em termos de novas perspectivas. Assim, com o passar dos anos, o profissional da contabilidade transformou-se, deixando de ser um simples "guarda-livros" para se tornar um profissional importante para a sobrevivência de uma empresa e do próprio Estado (Gouvêa \& Avanço, 2006). O profissional contábil deve, portanto, ser e passar a imagem de uma pessoa dinâmica, bem informada, deter as informações, saber utilizá-las e saber retransmiti-las (Schwez, 2001). Consoante a esse quadro, é inadmissível uma má conduta profissional.

Entretanto, mesmo com aspirações para a ética contábil, e a busca por conscientização dos contadores, ainda persistem profissionais que atentam contra o os princípios morais e éticos. Esse 
fato motivou o Ministério da Fazenda, quando criou em 1998 o COAF, cuja atuação é conjunta com demais entidades no combate à má conduta daqueles que prestam serviços contábeis. A missão do COAF é prevenir a utilização pelos setores econômicos de práticas de lavagem de dinheiro e financiamento do terrorismo, promovendo a cooperação e o intercâmbio de informações entre os setores público e privado.

As competências do COAF estão definidas nos artigos 14 e 15 da Lei n.. 9.613,/98, quais sejam: receber, examinar e identificar as ocorrências suspeitas de atividades ilícitas; comunicar às autoridades competentes para a instauração dos procedimentos cabíveis nas situações em que o Conselho concluir pela existência, ou fundados indícios, de crimes de "lavagem", ocultação de bens, direitos e valores, ou de qualquer outro ilícito; coordenar e propor mecanismos de cooperação e de troca de informações que viabilizem ações rápidas e eficientes no combate à ocultação ou dissimulação de bens, direitos e valores e disciplinar e aplicar penas administrativas.

Vale ressaltar que os serviços de contabilidade somente foram objeto de controle pelo COAF, através de envio de informações, em 2014. Neste ano se tornou obrigatório, para o setor econômico identificado pelos serviços de assessoria, consultoria, contadoria, auditoria e aconselhamento ou assistência, representados pela contabilidade, o envio de informações ao COAF. Tal obrigatoriedade surgiu do artigo 9º, inciso XIV da Lei n. ํ 9.613/98 e dos artigos 1ํe 12 da Resolução CFC n. ํㅜ 1.445/13. Contudo, não contempla os serviços de perícias e análises de riscos em organização que não seja seu cliente, exercidos pelo profissional ou a organização contábil. Por tal motivo, não será objeto de comunicação ao COAF. Como forma de evidenciar a preocupação do Estado brasileiro diante deste cenário, promulgou-se, mais recente, a Lei $\mathrm{n}^{\circ} 12.638 / 12$. O objetivo é dar mais rigor a Lei anterior, $\mathrm{n}^{\circ}$ 9.613/98, tornando mais eficiente a investigação e aplicação de penas para aqueles que incorrerem na prática de crimes de lavagem de dinheiro.

\section{METODOLOGIA}

O trabalho caracteriza-se como exploratório, com análise de dados pré-existentes no banco de dados do COAF, disponibilizados no sítio: <https://coaf.fazenda.gov.br/menu/estatisticas/comunicacoes $>$; sem que haja qualquer interferência. Destarte, visa identificar, relatar e comparar os dados da amostra oriunda de base de dados de fontes confiáveis e de notória reputação. O intuito foi informar sobre situações, fatos, opiniões ou comportamentos da população analisada.

Além disso, o trabalho levanta possibilidades de estudos futuros, pesquisando relações que não são estudadas. Relata ainda que não existem trabalhos que se debrucem sobe o recorte apresentado. A hipótese de pesquisa indica isso, levantando às inquietações e possíveis respostas. Já no que se refere aos procedimentos, o mesmo pode ser enquadrado como bibliográfico e documental a partir de análise de dados.

A abordagem do problema foi classificada como quantitativa, tendo em vista que se apoderou do teste de estatística descritiva. Desta forma, se apropriou da verificação de dados estatísticos para efetuar todas as análises.

\section{APRESENTAÇÃO E ANÁLISE DOS RESULTADOS}

Os resultados da pesquisa serão apresentados em quatro formas: a primeira com o estudo dos resultados das comunicações enviadas ao COAF entre os anos de 2004 a 2015; a segunda com os resultados da evolução dos comunicados em processos de investigação; terceiro as inter-relações institucionais no combate ao crime; e por fim os números de comunicações por segmento de atividade. 


\subsection{Comunicações enviadas ao COAF}

Na Tabela 1 abaixo apresentada, representa uma análise longitudinal das comunicações feitas por região no contexto geral Brasileiro durante 11 anos (entre os períodos de 2004 a 2015): 
Tabela 1- Comunicações enviadas ao COAF

\begin{tabular}{|c|c|c|c|c|c|c|c|c|c|c|c|c|c|}
\hline \multirow{2}{*}{ Regiões } & \multicolumn{12}{|c|}{2004 a 2015} & \multirow[t]{2}{*}{ Total } \\
\hline & 2004 & 2005 & 2006 & 2007 & 2008 & 2009 & 2010 & 2011 & 2012 & 2013 & 2014 & 2015 & \\
\hline \multirow[t]{2}{*}{ Norte } & 2326 & 7631 & 10654 & 15235 & 21533 & 32349 & 43010 & 53976 & 69713 & 72499 & 77582 & 79048 & 485556 \\
\hline & & $228 \%$ & $40 \%$ & $43 \%$ & $41 \%$ & $50 \%$ & $33 \%$ & $25 \%$ & $29 \%$ & $4 \%$ & $7 \%$ & $2 \%$ & \\
\hline \multirow[t]{2}{*}{ Nordeste } & 9752 & 18165 & 21499 & 30262 & 53281 & 82104 & 113107 & 145182 & 202425 & 199726 & 169402 & 180441 & 1225346 \\
\hline & & $86 \%$ & $18 \%$ & $41 \%$ & $76 \%$ & $54 \%$ & $38 \%$ & $28 \%$ & $39 \%$ & $-1 \%$ & $-15 \%$ & $7 \%$ & \\
\hline \multirow[t]{2}{*}{ Sudeste } & 45757 & 92884 & 120856 & 215461 & 423013 & 1401277 & 651148 & 803572 & 880673 & 700351 & 633855 & 699564 & 6668411 \\
\hline & & $103 \%$ & $30 \%$ & $78 \%$ & $96 \%$ & $231 \%$ & $-54 \%$ & $23 \%$ & $10 \%$ & $-20 \%$ & $-9 \%$ & $10 \%$ & \\
\hline \multirow[t]{2}{*}{ Sul } & 7603 & 18671 & 20015 & 50144 & 107089 & 186620 & 153691 & 192522 & 298450 & 227471 & 190897 & 208425 & 1661598 \\
\hline & & $146 \%$ & $7 \%$ & $151 \%$ & $114 \%$ & $74 \%$ & $-18 \%$ & $25 \%$ & $55 \%$ & $-24 \%$ & $-16 \%$ & $9 \%$ & \\
\hline \multirow[t]{2}{*}{$\begin{array}{l}\text { Centro } \\
\text { Oeste }\end{array}$} & 10013 & 19514 & 20324 & 23018 & 40449 & 99978 & 77391 & 93420 & 135467 & 86160 & 72805 & 82191 & 760730 \\
\hline & & $195 \%$ & $104 \%$ & $113 \%$ & $176 \%$ & $247 \%$ & $77 \%$ & $121 \%$ & $145 \%$ & $64 \%$ & $84 \%$ & $113 \%$ & \\
\hline \multirow[t]{2}{*}{ Total } & 75451 & 156870,6 & 193349 & 334123 & 645368 & 1802332 & 1038347 & 1288673 & 1586729 & 1286207 & 1144541 & 1249669 & 10801641 \\
\hline & & $108 \%$ & $23 \%$ & $73 \%$ & $93 \%$ & $179 \%$ & $-42 \%$ & $24 \%$ & $23 \%$ & $-19 \%$ & $-11 \%$ & $9 \%$ & \\
\hline
\end{tabular}

Fonte: Conselho de Controle de Atividade Financeira - COAF (adaptado).

Pela tabela acima pode-se notar que entre o período de 2004 a 2015 não se registra uma regularidade, nem tendência sobre o número total das comunicações enviadas ao COAF. Os números mostram que houve um período ascendente de 2004 até 2009 em todas as regiões do Brasil. Isso demonstra uma crescente evolução das comunicações. Essa ascendência pode ter sido oriunda pelo fato de ser uma novidade a implantação do COAF. Tendo em vista ser algo, é de se esperar um crescente aumento no número de organizações obrigadas a enviar informações ao COAF. Já o decréscimo pode ser explicado pela desobrigação de envio de informações ao COAF por parte de algumas dessas organizações, devido o não cumprimento das exigências legais para obrigatoriedade. Logo que foi instituído o COAF, muitas entidades ficaram receosas quanto ao envio ou não de informações. Isso pode ter motivado um crescimento das informações enviadas por região geográfica logo no início, mas que depois foi decrescendo, porque muitas das entidades perceberam que não eram obrigadas a enviar as informações.

Após 2008 mostra-se uma queda não regular das informações comunicada. Vale destacar que nos anos de 2013 e 2014 houve uma queda significativa de um ano comparando ao anterior, quando se analisa as informações encaminhadas por todas as regiões brasileiras. Uma queda muito grande no envio das informações pode ser observada no ano de 2010 em relação a 2009, com um valor de $42 \%$ a menor.

Ao analisar os dados com mais detalhes, sob a perspectiva individual da região geográfica, pode-se notar que as quedas comparativas do geral registrada nos anos de 2013 e 2014 foram acentuadas devido às quedas das comunicações em três regiões brasileiras: nordeste, sudeste e sul. De fato, isso indica que essas regiões não mantiveram regularidade no envio de informações. Neste mesmo período, diferentemente das demais, a região centro-oeste apresentou um grande crescimento no envio de informações. A região norte, por sua vez, não apresentou um crescimento tão expressivo como a região do centro-oeste, contudo registrou um leve crescimento.

Em linhas gerais, nos períodos analisados, as regiões centro-oeste e norte estão sendo as regiões com maior regularidade e crescimento no número de comunicações enviadas. Desta forma, conclui-se que existe um fortalecimento e comprometimento dos profissionais e entidades contábeis na promoção e combate a crimes nestas regiões. Afinal, quanto mais comunicações são enviadas aos órgãos de controle e fiscalização, maior será a expectativa punitiva para como os responsáveis por 
má fé e por crimes fiscais, entre outros que atentam contra a ordem tributária, e ao próprio Estado brasileiro como um todo.

\subsection{Resultados das ações de intervenção do COAF}

Esta análise irá apresentar como o COAF transforma as informações recebidas em reais processos no combate e intervenção aos crimes.

Tabela 2 - Principais resultados do COAF entre 2012 e 2014

\begin{tabular}{|c|c|c|c|c|}
\hline & \multicolumn{3}{|c|}{2012 a 2014} & \multirow{2}{*}{ Total } \\
\hline & 2012 & 2013 & 2014 & \\
\hline Comunicações recebidas dos setores obrigados & 1144542 & 1286233 & 1587427 & 4018202 \\
\hline Relatórios de Inteligência Financeira (RIF) produzidos & 3178 & 2450 & 2104 & 7732 \\
\hline Comunicações relacionadas nos RIF & 105259 & 108962 & 85759 & 299980 \\
\hline Pessoas relacionadas nos RIF & 77049 & 52812 & 15772 & 145633 \\
\hline Intercâmbio com autoridades nacionais & 2971 & 3107 & 2421 & 8499 \\
\hline Intercâmbio realizados com UIF (Rede de Egmont) & 160 & 170 & 164 & 494 \\
\hline Bloqueio de recursos (em $\mathrm{R} \$$ milhões) & 484 & 927,5 & 61,4 & 1473 \\
\hline Averiguações Preliminares concluídas & 73 & 27 & 16 & 116 \\
\hline Cadastramento de pessoas reguladas & 1748 & 2685 & 771 & 5204 \\
\hline Processo Administrativo Puntivo instaurados & 45 & 9 & 6 & 60 \\
\hline Processo Administrativo Puntivo julgados & 12 & 10 & 18 & 40 \\
\hline Advertências aplicadas & 21 & 17 & 18 & 56 \\
\hline Multas aplicadas (em R $\$$ mil) & 211,1 & 624,4 & 453,2 & 1289 \\
\hline
\end{tabular}

Fonte: Conselho de Controle de Atividade Financeira - COAF.

A tabela apresentada acima demonstra os resultados do tratamento das informações recebidas pelo COAF no período compreendido entre 2012 e 2014. Com os resultados pode-se apontar que dos 13 itens analisados, 8 deles apresentaram quedas acentuadas, equivalendo a $61 \%$ das avaliações. A preocupação especial deve ser dada às multas aplicadas, pois as mesmas apresentam um aumento entre 2012 e 2013, em seguida, talvez por uma falta de atenção, correção e tratamento das informações, as multas apresentam uma queda. Esta queda pode ter sido oriunda da correção de informações anteriormente encaminhas ao COAF, e maior diligência e preocupação com as informações por parte das entidades e profissionais. Os recursos bloqueados, por conta da ação do COAF, tendo em vista as informações encaminhadas, apresentaram um aumento de aproximadamente $92 \%$ entre 2012 e 2013. Em 2014 caem para apenas 33\% em relação a 2013, corroborando com a atuação eminentemente punitiva. Neste ínterim, a queda no bloqueio dos recursos mostra que as averiguações preliminares e processos instaurados foram reduzidos. Sendo assim, um enfraquecimento institucional no combate aos crimes contra o erário público pode ser notado.

Os dados mostram-se preocupantes, pois mesmo com o crescimento das comunicações recebidas pelo COAF, ainda são incipientes as ações deste órgão na efetividade das ações de fiscalização, controle e punição. Os números mostram uma redução dos intercâmbios "troca de informação" com outras autoridades, tais como Polícia Civil, Polícia Federal, Receita Federal, dentre outros. Como veremos a seguir: 
Tabela 1 - Intercambio com autoridade

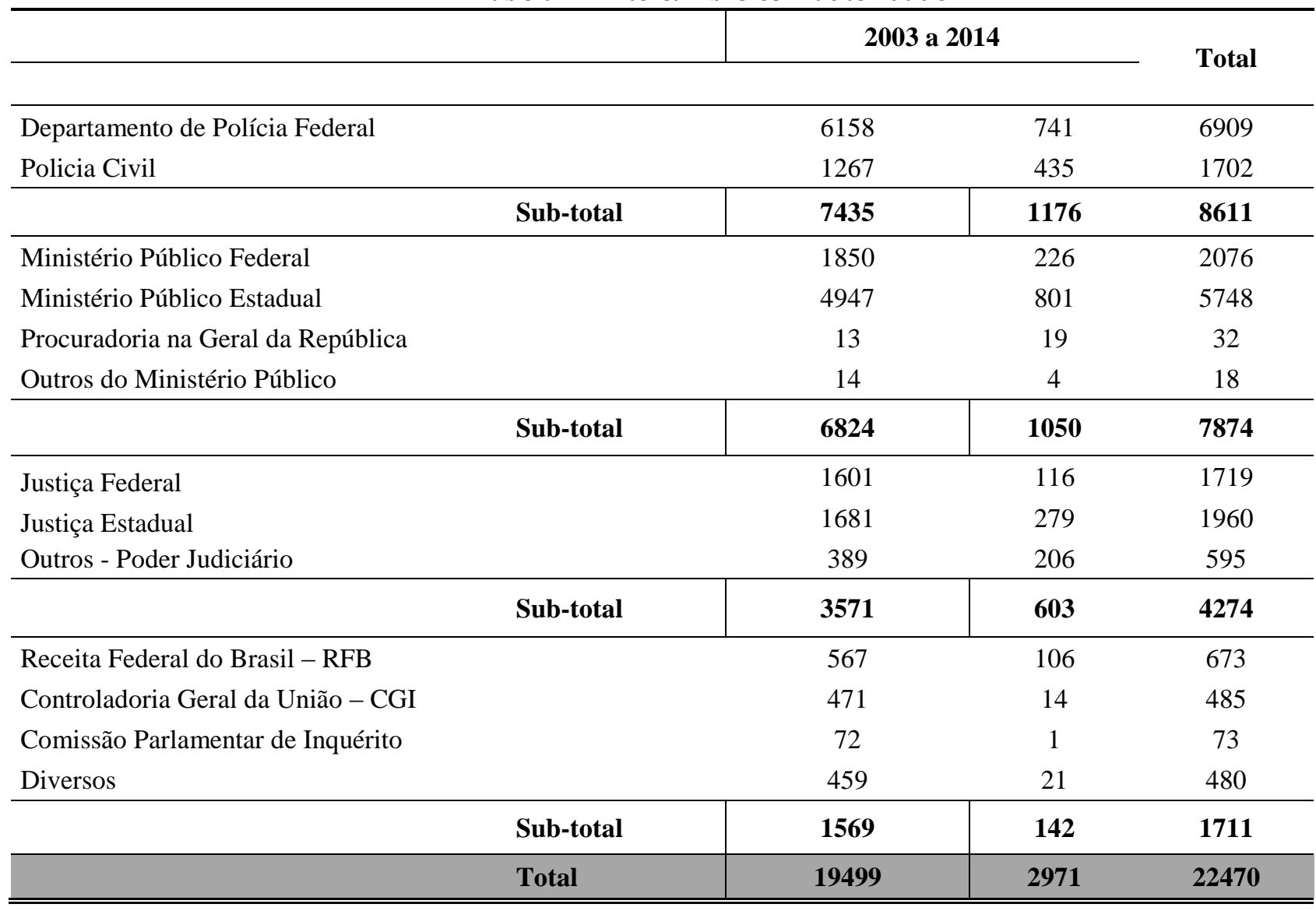

Fonte: Conselho de Controle de Atividade Financeira - COAF

A tabela disponível do COAF não permite uma análise horizontal das informações, afinal não possibilita uma análise comparativa temporal dos anos anteriores, principalmente no período agregado entre 2003 a 2013. De qualquer forma, os números totais de intercâmbio são insignificantes em relação ao número de comunicados recebidos. Entretanto, o intercâmbio com a Polícia Federal foi o que mais sobressaiu seguido pelo Ministério Público Federal. Isso pode ser considerado um agravante, pois no processo de fiscalização, controle e punição dos responsáveis, esta troca de informações constitui elo com os principais órgãos responsáveis pela investigação e conclusão das informações processadas.

Neste contexto, vivemos num ambiente no qual as investigações de denúncia contra crimes fiscais são evidentes na mídia, sendo comum nos noticiários. No entanto, alguns órgãos de controles e fiscalização não conseguem desenvolver suas atividades intrínsecas. Tal fato corrobora com a existência de impunidade na sociedade. De certa forma, os profissionais responsáveis pelo envio destas informações podem sentir-se desestimulados, motivados pela falta de averiguação e conclusão das comunicações enviadas.

Ao analisar as advertências confrontadas com os comunicados, são nítidos os resultados apresentados. Dentre casos entre 2012 a 2014 apenas 1\% deles foram passíveis de advertência. Assim, é evidente que, mais uma vez, a investigação e impunidade ainda é muito grande no Estado brasileiro. O contexto indica uma necessidade de mudança de postura frente às informações recebidas e seu posterior tratamento. 


\subsection{Comunicações Recebidas por Setores Econômicos Obrigados}

Nesta análise, percebe-se abaixo um quadro comparativo de comunicação por órgãos reguladores no sistema financeiro nacional entre outras instituições vinculadas, mostrando importantes, pois permite identificar a contribuição no combate ao crime por órgão regulador.

Tabela 4 - Comunicações Recebidas por Setores Econômicos Obrigados (Art.9o da Lei no 9.613/98).

\begin{tabular}{|c|c|c|c|c|c|c|c|c|}
\hline $\begin{array}{l}\text { Órgão } \\
\text { Regulador }\end{array}$ & Setor Econômico & $\begin{array}{c}1998 \mathrm{a} \\
2010\end{array}$ & 2011 & 2012 & 2013 & 2014 & Total & $\%$ Utll \\
\hline \multicolumn{9}{|c|}{ Operações Aplicadas } \\
\hline BACEN & Sistema Financeiro & 184678 & 37237 & 41819 & 53244 & 57455 & 324433 & 15,92 \\
\hline $\mathrm{CFC}$ & $\begin{array}{l}\text { Contador - Serviços de Assessoria, } \\
\text { Consultoria, } \\
\text { Contadoria, Auditoria, Aconselha- } \\
\text { mento ou } \\
\text { Assistência }\end{array}$ & - & - & - & - & 105 & 105 & 8,57 \\
\hline COFECI & $\begin{array}{l}\text { Promoção imobiliária Compra/Venda } \\
\text { Imóveis }\end{array}$ & 15789 & 3768 & 5473 & 4445 & 3303 & 32779 & 2,66 \\
\hline COFECON & Assessoria, Consultoria, etc & - & - & - & - & - & 0 & 0 \\
\hline CVM & Mercado de Valores Mobiliários & 4264 & 1176 & 1139 & 1616 & 2181 & 10376 & 10,36 \\
\hline DPF & Transporte e Guarda de Valores & 5 & 17 & 1014 & 723 & 1877 & 3636 & 1,05 \\
\hline DREI & Juntas Comerciais & - & - & - & - & 1 & 1 & 0 \\
\hline PREVIC & Previdência Complementar & 33403 & 6076 & 7433 & 7152 & 8975 & 63039 & 0,43 \\
\hline SEAE & Loterias e Sorteios & 150322 & 152128 & 195499 & 170789 & 4497 & 683235 & 0,59 \\
\hline \multirow{2}{*}{ SUSEP } & Mercado Segurador & 2075699 & 332606 & 467512 & 125451 & 45255 & 3046523 & 1,33 \\
\hline & Total Reguladores Próprios & 2414160 & 543008 & 719889 & 363421 & 123649 & 4164127 & - \\
\hline \multirow{7}{*}{ COAF } & Bens de luxo ou de Alto Valor & - & 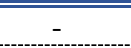 & - & 3589 & 4605 & 8194 & 0,77 \\
\hline & Cartões de Crédito & 1257 & 558 & 14166 & 26368 & 31396 & 73745 & 0,73 \\
\hline & $\begin{array}{l}\text { Factoring e Securitização de Ativos, } \\
\text { Títulos ou Recebíveis Mobiliários }\end{array}$ & 70381 & 15026 & 17114 & 32376 & 15890 & 151787 & 6,09 \\
\hline & Jóias, Pedras e Metais Preciosos & 74 & 28 & 176 & 321 & 453 & 1052 & 3,23 \\
\hline & Objetos de Arte e Antiguidades & 13 & 3 & 19 & 9 & 24 & 68 & 2,94 \\
\hline & Remessa Alternativa de Recursos & 5590 & 1069 & 24170 & 61 & 435 & 31325 & 3,22 \\
\hline & $\begin{array}{l}\text { Serviços de Assessoria, Consultoria, } \\
\text { Auditoria } \\
\text { Aconselhamento ou Assistência }\end{array}$ & - & - & 1 & 8 & 15 & 24 & 8,33 \\
\hline & Total Regulador COAF & 77315 & 16684 & 55646 & 62732 & 53818 & 266195 & $2 \mathbf{2 5 , 3 1}$ \\
\hline \multicolumn{2}{|r|}{ Outros Setores Previstos na Lei } & - & - & 23 & 86 & 13 & 128 & 0,78 \\
\hline \multicolumn{9}{|c|}{ Operações em Espécie ${ }^{1}$} \\
\hline BACEN & Sistema Financeiro & 1824578 & 729395 & 811869 & 859994 & 967056 & 5192892 & 7,09 \\
\hline Total Geral & & 4316053 & 1289087 & 1587233 & 1286233 & 1144542 & 9620342 & - \\
\hline
\end{tabular}

Fonte: Conselho de Controle de Atividade Financeira - COAF.

No que tange às informações comunicadas por órgãos reguladores, nota-se que os órgãos do sistema financeiro bancário são responsáveis por maior volume de comunicações encaminhadas no ano 2014. Considerando-se o acumulado dos períodos analisados, quem mais cooperou com informações foi a Superintendência de Seguros Privados (SUSEP). Destarte, sobre o crivo da própria $\mathrm{COAF}$, as informações das empresas de cartão de crédito representam uma grande parcela das comunicações, seguidas das operações de factoring e securitização de ativos e/ou títulos.

Igualmente, um dado preocupante refere-se à participação dos profissionais de consultoria e contabilidade. Para esta modalidade de serviço, a obrigatoriedade de envio de informações ao COAF iniciou-se em 2014. Já que esta obrigatoriedade é nova, os serviços de contabilidade apenas 105 comunicações foram feitas ao COAF. Destas apenas 8,57\% foram, de fato, úteis. Este dado pode nos indica que este setor ainda não coopera com o envio dos comunicados. Por outro lado, demonstra 
um grande desafio para a classe contábil, e cria uma consciência acerca da relevância das informações ao Estado. Reafirma a necessidade de avaliar a atuação deste setor econômico a partir da percepção do quanto é importante encaminhar informações para a fiscalização do erário. Além disso, permite uma maior atuação do profissional da contabilidade, no que se diz respeito ao seu compromisso ético profissional, numa tentativa de contribuir para evitar ou minimizar as práticas de lavagem de dinheiro e demais crimes contra a ordem tributária.

\section{CONCLUSÃO}

De todo o exposto, conclui-se que o os resultados alcançados depois da obrigatoriedade de envio de informações pelos profissionais contábeis ao Estado brasileiro, através do COAF, ainda se encontram em estado latente, e não podem prescindir duma análise temporal maior, pois a obrigatoriedade de envio das informações contábeis iniciou em 2014. Entretanto, a aplicação como ferramenta nova e que traça, mesmo que num estado inicial e incipiente, um perfil das informações de contabilidade ante uma realidade nova é indiscutível.

Por essa razão, já se pode afirmar que os resultados alcançados, após a obrigatoriedade de envio de informações pelos profissionais contábeis ao COAF, caminham para a procura de respostas a questões polêmicas, como o comportamento deste segmento diante dum Estado, cuja prerrogativa fiscalizadora e punitiva faz-se crescente. Ainda, o estudo motiva a criação duma consciência nos profissionais e entidades contábeis em relação ao papel da contabilidade como ferramenta útil no combate ao crime contra a ordem tributária. Quanto à urgência e repercussão do tema, sobretudo no seio da sociedade, é necessário maior enfoque das futuras pesquisas, principalmente pelo fato do envio de informações ao COAF ser recente para o segmento de contabilidade. Uma análise dos eventos pós adoção desta obrigatoriedade de envio de informações do segmento contábil é indiscutível.

Sugerem-se algumas recomendações para pesquisas futuras. É necessária uma abordagem maior sobre os resultados da utilização das informações contábeis enviadas ao COAF e investigar as possíveis medidas adotadas ou a serem adotadas pelo Estado brasileiro após o recebimento e tratamento das informações contábeis recebidas.

\section{REFERÊNCIAS}

Avritzer, L. (2007). Sociedade Civil, Instituições Participativas e Representação: da Autorização à Legitimidade da Ação. Revista de Ciências Sociais, Rio de Janeiro, 50(3), 443-464.

Brasil. (2016). Constituição, 1988. Constituição da República Federativa do Brasil. Brasília. São Paulo: Revista dos Tribunais.

Brasil. (2016b). Constituição Federal - Código Penal - Código de Processo Penal. Organizador: Luiz Flávio Gomes. (3a ed) São Paulo: Revista dos Tribunais.

Brasil. (2016c). Lei 7.170, de 14 de dezembro de 1983. Define os Crimes Contra a Segurança Nacional, a Ordem Política e Social, Estabelece o seu Processo e Julgamento e dá Outras Providências. Recuperado em 27 de janeiro, 2016, de www.senado.gov.br.

Brasil. (2016d). Lei 8.137, de 27 de dezembro de 1990. Define Crimes Contra a Ordem Tributária Econômica e Contra as Relações de Consumo, e dá Outras Providências. Recuperado em 29 de janeiro, 2016, de www.senado.gov.br. 
Brasil. (2016e). Lei 9.249, de 26 de dezembro de 1995. Altera a Legislação do Imposto de Renda das Pessoas Jurídicas, bem como da Contribuição Social sobre o Lucro Líquido, e dá Outras Providências. Recuperado em 25 de janeiro, 2016, de www.senado.gov.br.

Brasil. (2016f). Exposição de Motivos n.692 /MJ, de 18 de dezembro de 1996. Exposição de Motivos da Lei 9.613/98. Recuperado em 25 de janeiro, 2016, de www.fazenda.gov.br/coaf.

Brasil. (2016g). Lei n. 9.613, 3 de março de 1998. Dispõe sobre os Crimes de Lavagem ou Ocultação de Bens, Direito ou Valores. Recuperado em 27 de janeiro,2016, de www.senado.gov.br.

Brasil. (2016h). Decreto n. 2.799, de 8 de outubro de 1998. Aprova o Estatuto do Conselho de Controle de Atividades Financeiras [COAF]. Recuperado em 2 de fevereiro,2016, de www.senado.gov.br.

Brasil. (2016i). Lei Complementar n. 105, 10 de janeiro de 2001. Dispõe sobre o Sigilo das Operações de Instituições Financeiras e dá Outras Providências. Recuperado em 2 de fevereiro,2016, de www.senado.gov.br.

Barbosa, R. S.; Araujo, T. S.; Andrade, M. E. M. C.; Ávila, L. A. C. (2014). As Implicações do Não Agir Ético no Planejamento Tributário. Revista de Auditoria, Governança e Contabilidade. 2(3), 6071.

Britto, C. A. (1992). Distinção entre Controle Social do poder e Participação Popular. Revista de Direito Administrativo. Brasília, (189), 115-122.

Doost, R. K. (1999). Advances in Accounting and Communication - A Historical Review. Managerial Auditing Journal. 14(8), 438-441.

Gohn, M. G. (2010). Movimentos Sociais e Redes de Mobilização Civis no Brasil Contemporâneo. Petrópolis: Vozes.

Golden, T. W.; Skalke, S. L.; Clayton, M. M. (2011). A guide to forensic acconunting investigation. (2a ed) Nova Jersey: Wiley.

Gouvêa, P. E; Avanço, L. (2006). Ética e Fraudes Contábeis. Unopar Científica-Ciências Jurídicas e Empresarias. Londrina, 7, 85-91.

Júnior, I. J. N.; Moreira, E. M. S. (2011). Perícia Contábil: uma Ferramenta de Combate ao Crime Organizado. Revista de Educação e Pesquisa em Contabilidade. (ed. Especial) 5,126-153.

Lehman, C. R.; Okcabol, F.(2005) Accounting for crime. Critical perspectives on accounting. 16, 613639.

Meirelles, h. L. (2003). Direito administrativo brasileiro. (28a ed.) São Paulo: Malheiros.

Minayo, M. C. S. O desafio do conhecimento. (1989). Tese (doutorado), Rio de Janeiro: Escola Nacional de Saúde Pública, Fundação Oswaldo Cruz, Rio de Janeiro.

Napolitano, G., Moran, M., Cohen, A. (2002). Demand for Forensic Accounting Intensifies. New York: Goldman Sachs.

Oliveira, D. (2007). A Imagem do Contador no Brasil: um Estudo sobre sua Evolução Histórica. Rca - Revista de Controle e Administração [RAC] 3(1). 
Oliveira.D. (2012). A Relação entre o tipo Penal e a Prova Pericial Contábil: Evidências nos Laudos Contábeis da Perícia Criminal Federal sobre o Crime de Apropriação Indébita Previdenciária. Faculdade de Economia, Administração e Contabilidade - Departamento de Contabilidade e Atuária - tese. São Paulo.

Ribeiro, J. A. P. (2002). O Papel do Direito na Contabilidade. Revista da FARN do Rio Grande do Norte. Natal, (2)1, 81-88.

Roncato, C. J. (2006). Sonegação Fiscal e Lavagem de Dinheiro. Monografia. (Curso de pós- graduação latu sensu em Direito Econômico da Regulação Financeira) - Universidade de. Brasília. Brasília, Distrito FederalSchwez, N. (2001). Responsabilidade Social: Meta e Desafio do Profissional da Contabilidade para o Próximo Milênio. Revista Brasileira de Contabilidade, Brasília, 30 (130),71-85.

Silva, L. M. (2012). Contabilidade Forense. (1a ed.) São Paulo: Atlas.

Tatagiba, L. (2010). Desafios da Relação entre Movimentos Sociais e Instituições Políticas o Caso do Movimento de Moradia da Cidade de São Paulo - Primeiras Reflexões. Revista Colombia Internacional, ( 71), 63-83.

Valente, L. C. A. (2003). Responsabilidade Subjetiva do Contabilista no Novo Código Civil. Gazeta Mercantil, São Paulo, 21 mar. 2003. 